\title{
The Health Risk from Drinking Spring and Bottled Artesian Water of Central Russia
}

\author{
S.A. Buymova*, A.G. Bubnov \\ Ivanovo State University of Chemistry and Technology \\ *Corresponding Author: byumova@mail.ru
}

Copyright $@ 2013$ Horizon Research Publishing All rights reserved.

\begin{abstract}
Indicators of quality and safety, as well as the useful properties of spring water, artesian bottled water and water from a municipal water supply systems are assessed. All the investigated samples of bottled drinking well water satisfy regulatory requirements for defined quality parameters. Biotesting analysis of the samples of water using two test organisms: crustacean Daphnia Magna and freshwater aquarium fish Poecillia Reticulata Peters confirmed the presence of different pollutants in spring water. Risks of oral use of investigated water are calculated. In terms of the quality of groundwater for the study area is characterized by Russian acceptable level of risk, which indicates a moderate anthropogenic pressure on ecosystems and the environment.
\end{abstract}

Keywords Spring Water, Drinking Water, Bottled Water, The Health Risks, Biotesting

\section{Introduction}

One of the world's most important problems in the XXI century is the problem of quality and affordable water supply. This problem is exacerbated by the growth of cities and the population [1]. In some regions of Russia as a result of deterioration of water supply systems, tap water does not always meet the necessary standards and requirements. Therefore it is more and more popular, both in urban and rural residents, to use water from natural sources - springs and artesian drinking water, packaged in plastic containers (including the preparation of baby food).

\section{Methodology}

Earlier it was noted that in Russia there is no methodology for integrated assessment of drinking water as spring water and bottled artesian [2]. The integral indicator is evaluation of value and risk[3].It was therefore a comparative characterization of the quality of drinking water, selected from 50 natural springs (№№ $1-50$ ), located in the watershed of the Volga River in the Central Federal District of Russia, bottled and tap water. Each of the selected water samples was analyzed by 44 indicators of quality (for compliance with hygiene standards). Sampling, sample preparation and analysis of samples were carried out in accordance with the existing Russian regulatory documents. In addition to chemical was held biotesting analysis of the samples of water using two test organisms: crustacean Daphnia Magna and freshwater aquarium fish Poecillia Reticulata Peters. Now in Russia there is no standard method to categorize the quality of springs and artesian waters on the basis of biotesting analysis, so the classification applied to surface water bodies was used. However, the methods of biotesting are applicable for any water samples. As the ranking criterion is precisely the death of test organisms, to classify the studied waters were used only on the results of bioassays Daphnia Magna, since the death of Poecillia Reticulata Peters was $0 \%$.

Based on the experimental data the value of the potential danger (PD) and the values of the individual risk so foral use of the samples of water were calculated.

The methodology for calculating the PD includes determining4 components:

K1-favourable physical and organoleptic properties (smell, taste, color, turbidity, and $\mathrm{Fe}, \mathrm{Mn}$, permanganate oxidation, etc.);

K2-harmlesschemical composition(F-, NO2-, NO3-, NH3, etc.);

K3-physiologicalusefulness of the content of minerals and microelements(total mineralization, total hardness, HCO3-, SO42-, Cl-, etc.);

$\mathrm{K}_{4}$-safety in epidemio logical terms(bacteriological: total microbial count (TMC) - number of mesophilic aerobic and facult ative anaerobic microorganismsetc.).

According to this methodology, the greater the value of the componentK3, the more water is considered "physiologically full" and the smaller the value of the water is consideredless dangerous when it is used. Note that one of the disadvantages of this method is the lack of consideration of the effect of summation for pollutants present in the samples of drinking water. Based on the values obtained by calculation PD can be further evaluate the risks of adverse 
effects, and morbidity(gastrointestinal tract, cardiovascular system, etc.) in a subject by use of samples of water, however this procedure is not prediction model of cancer diseases.

To determine the amount of damage to human health from these or other adverse factors, was used the approach proposed by B.L. Cohen, which includes the calculation of reduction loss of life expectancy(LLE) due to the deterioration of its quality[4]:

$$
\mathrm{LLE}=\mathrm{R} \cdot \mathrm{L}
$$

$\mathrm{R}$-the probability of occurrence of a hazardous event under consideration (the value of the risk of systemic toxicity by oral use of water), the share of units.; L-expected the rest of life, year.

Knowing the value of LLE, the damage can be calculated, expressed in monetary terms, the damage human health(damage from LLE):

$$
\mathrm{Y}=\mathrm{LLE} \cdot \mathrm{SVL}
$$

SVL - statistical value of life (RUB), which is calculated by the formula:

$$
\mathrm{SVL}=(\mathrm{GDP} \cdot \mathrm{T}) / \mathrm{N}
$$

GDP (RDP) -Gross Domestic Product (Regional Domestic Product), RUB; T -average life expectancy of a year; $\mathrm{N}$ -population, people. The values obtained in this way are relative and vary from year to year.

\section{Results and Discussion}

Chemical and microbiological analysis of samples of spring water showed that in $76 \%$ of samples were found to contain various kinds of pollutants, and the sources located in the area of low anthropogenic influence (rural areas) are much less susceptible to contamination than springs, which are in the urbanized territories.

Comparison of the concentration of pollutants contained in the water samples was carried out with the value of the maximum permissible concentration (MPC) or standard(N)in $\mathrm{mg} / \mathrm{l}$-this is the maximum level at which the consumption of toxic substances does not cause adverse effects to the human. MPC(N)substances present in the water of centralized and decentralized sources, set the standard documentation, operating in the Russian Federation.

In most cases in spring water samples was observed excess of the normative content of the following indicators of quality(the components are presented in order of decreasing concentrations): TMC(up to $30,0 \mathrm{~N}$ ), the content of $\mathrm{Li}+$ (up to 7,0 MPC), the value of permanganate oxidation(up to6,0 N),total hardness(up to 5,0 MPC), total mineralization(dry residue) and $\mathrm{Mn}$ total content(up to 3,5MPC), the content of surfactants (up to 3,0 MPC), $\mathrm{Zn}^{2+}$ and Fe total, Ni total(up to2,0 MPC), $\mathrm{Na}+$ (up to 1,6 MPC), $\mathrm{NO}^{3-}$ (up to 1,5 MPC)and $\mathrm{NH} 4+($ up to 1,3 MPC).
The dynamics of the complex quantity of potential danger (risk), calculated on the basis of evidence of specific pollutants in the three springs of the city of Ivanovo, showed that over the entire observation period $(2003$ - 2011), the maximum amount of risk could be in 2006 (Fig. 1). That may be due to technogenic pollution of the city because of the hard work and the development of industry in that time.

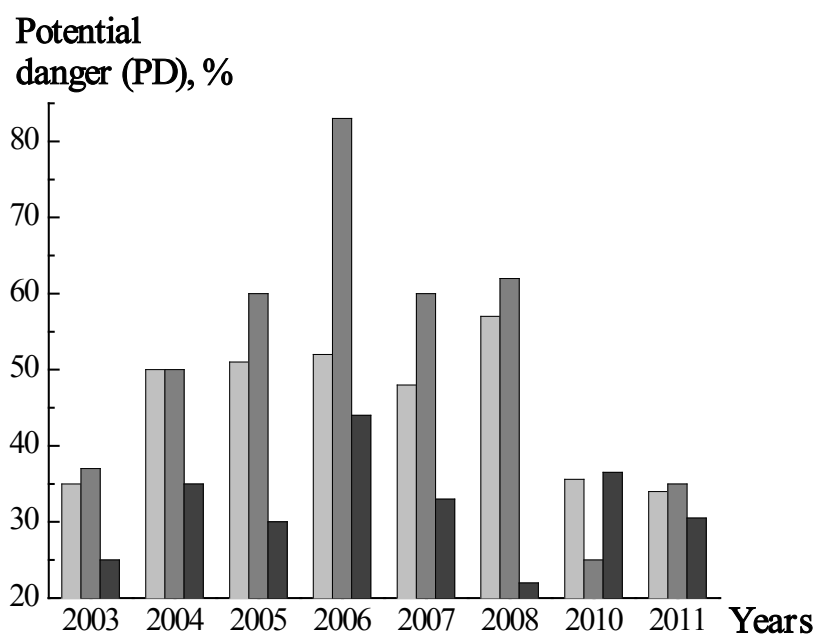

Figure 1. The averaged values of the potential danger to water springs №№ 1 - 3 in the town of Ivanovo (observation period 2005 - 2008, 2010, 2011).

$\square$ - spring № 1; $\square$ - spring № 2; $\square$ - spring № 3.

Note that all the investigated samples of bottled drinking artesian water satisfy regulatory requirements for quality criteria.

Based on the chemical composition of the samples of bottled water carcinogenic substances (such as $\mathrm{Cd}, \mathrm{Pb}, \mathrm{As}$, etc.) was calculated individual lifetime risk of dying (LR)by the formula:

$$
\mathrm{LR}=\mathrm{CDI} \cdot \mathrm{SF}
$$

CDI -mean daily dose of pollutants entering the human organism through the regular use of oral examined samples of water, $\mathrm{mg} /(\mathrm{kg} \cdot \mathrm{d})$;

$\mathrm{SF}-$ carcinogenic potential factor $(\mathrm{mg} /(\mathrm{kg} \cdot \mathrm{d}))-1$.

CDI heavy metals in the human organism when using drinking water were calculated by the following formula:

$$
\mathrm{CDI}=\frac{\mathrm{Q} \cdot \mathrm{IR} \cdot \mathrm{EF} \cdot \mathrm{ED}}{\mathrm{BW} \cdot \mathrm{AT}}
$$

Q - the concentration of heavy metals in drinking water, $\mathrm{mg} / \mathrm{l}$; IR - the average daily consumption of drinking water, $\mathrm{ml} /$ day; EF - Impact frequency, days/year; ED - exposure time(year), calculated as the difference between the average life expectancy in the region and the average age in; BW the average weight of the human body, kg; AT - averaging time, days.

These standards are recommended by Deutsche Gesselschaft fur Ernahrung (DGE),Food and Nutrition Board (FNB)and Scientific Commitee on Food (SCF)of the European Union[5]. 
For all the studied samples of bottled water LR was relatively low. On the basis of experimental data on the chemical composition of bottled water, according to the method proposed by B. Cohen [4], the values were calculated population risk(Rpopul)that correspond to risks, caused by an earthquake or flood:

$$
\text { Rpopul }=\mathrm{LR} \cdot \mathrm{N}
$$

$\mathrm{N}$ - population of the region

Calculations reduction of life expectancy (LLE), and the likely damage to the individual from the oral use of bottled water showed that the values of LLE and damage to this risk can be described as minimal.

The estimate of the risk of samples analyzed and bottled spring water showed that at constant oral use spring water quality does not meet the regulatory requirements, there may be a variety of diseases of the digestive system, cardiovascular system, etc. While bottled water was not only "safe", but "useful" in terms of the value of the physiological
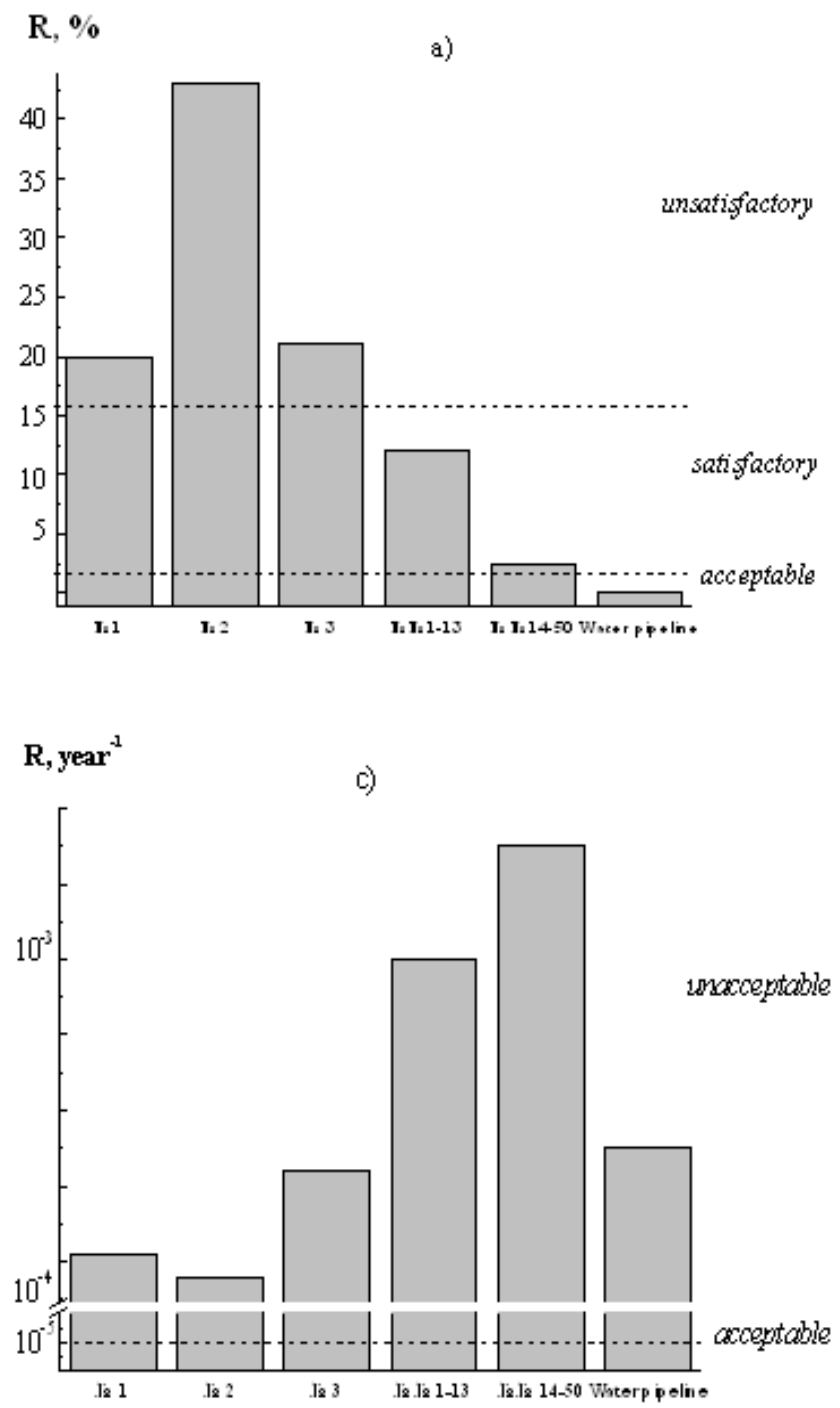

usefulness, i.e. content required by the human organism substances and microelements.

It was confirmed that the size of potential danger can be ranked analyze samples of drinking water (in declining order of quality): artesian bottled water $\rightarrow$ spring water from sources located in the countryside $\rightarrow$ water from a municipal water supply system $\rightarrow$ spring water from sources located in the cities.

In addition, was calculated the risk of carcinogenesis by oral use of spring and tap water (Fig. 2). For water sources, Ivanovo, (Fig. 2) tended to increase the amount of risk of morbidity (risk of adverse organoleptic effects of chronic toxicity and systemic toxicity) of the oral use of spring water during $2003-2011$. The level of risk of immediate action for springs, Ivanovo, mostly classified as "unsatisfactory" (Fig. $2 \mathrm{a}$ ), and the risk of chronic intoxication - "disturbing" and "dangerous" (Fig. 2b), a carcinogenic effect - an "unacceptable "(Fig. 2c).
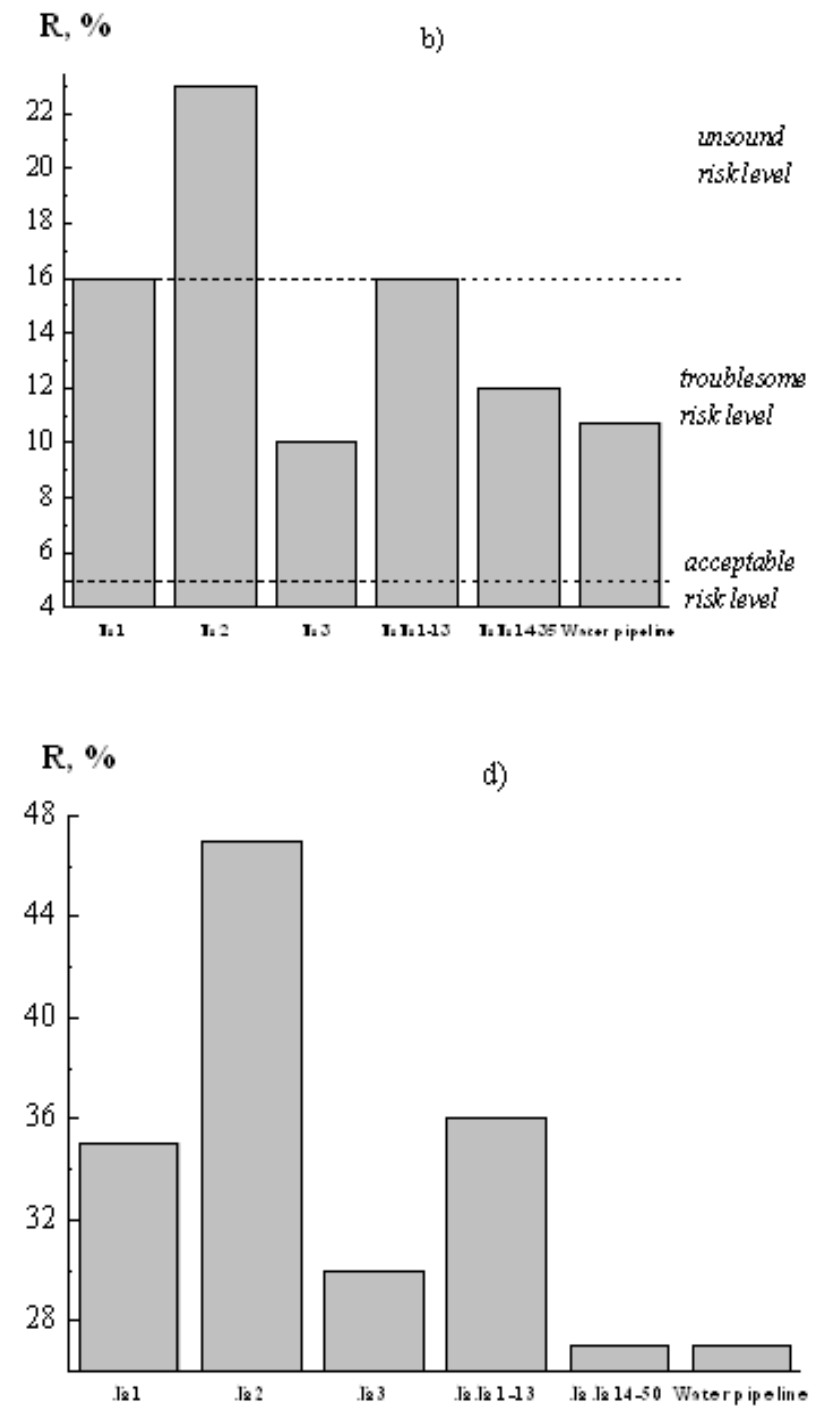

Note: №№ 1 - 13 (13 springs in the cities of Ivanovo region); №№ 14 - 50 (37 springs in rural areas of the Ivanovo region)

Figure 2. The risks of adverse organoleptic effects (immediate release) - (a), chronic intoxication - (b), a carcinogenic effect - (c) and risk of general toxicity (cumulative risk) - (d) of the population from the oral use of spring and tap water (observation period 2003 - 2008, 2010, 2011). 
Table 1. Assessment of the investigated water sources on the basis of the analysis on the death biotesting crustacean Daphnia Magna

\begin{tabular}{|c|c|c|c|c|}
\hline \multirow{2}{*}{ № } & \multirow{2}{*}{\multicolumn{2}{|c|}{ Drinking water source }} & \multicolumn{2}{|c|}{ Parameter } \\
\hline & & & $\%$ of death within $96 \mathrm{~h}$ of exposure & Level of contamination \\
\hline 1 & & novo & 60 & high \\
\hline 2 & \multirow{3}{*}{ Ivanovo } & Spring № 2 & 40 & high \\
\hline 3 & & Spring № 3 & 30 & increased \\
\hline 4 & & Spring № 1 & 30 & increased \\
\hline 5 & \multicolumn{2}{|c|}{ Tap water after filtration and boiling } & 10 & low \\
\hline
\end{tabular}

Similarly, bottled water has been assessed lifetime risk of death for the individual samples of spring water, which can be attributed to the average. Overall, was estimated the value of economic damage and risks point to a slight extent of pollution of drinking water (spring and bottled water) investigated region of Russia.

Results of biotesting drinking water sample analysis are shown in Table.

Thus, the results of biotesting confirmed the previously obtained computed information about the possible risks of oral use of spring and tap water.

\section{Conclusion}

Based on these results, the following conclusions were made: methodology for the calculation of individual risk (based on reduction in life expectancy [4], i.e. damage from worsening quality of life) of the pre-oral use is not prepared well water, can be used to support the costs of environmental protection, as well as measures to ensure the safety people, empowered to protect the health and well-being of the population. In general, in terms of the quality of ground water for the study area by Russia is characterized acceptable risk level ${ }^{1}$, which indicates a moderate technogenic impact on ecosystems and the environment.

\section{REFERENCES}

[1] URL: http://transhumanity.net/articles/entry/water-wars-nine-thirst y-regions-where-h20-conflict-is-threatening (Water Wars Nine Thirsty Regions where H2O Conflict is Threatening // Trans humanity, Posted: Thu, January 10, 2013 / By: Hank Pellissier).

[2] Buymova, S.A. Assessing the quality of Russia's spring water / S.A. Buymova, A.G. Bubnov // Water 21. - 2012. August. - P. 74.

[3] Global Health Risks/ Results. Part 2 / World Health Organization, 2012. - P. $9-27$.

[4] Cohen, B.L. Catalog Of Risks Extended And Updated / B.L.Cohen // Health Physics. - 1991. - Vol. 61. - P. 89 96.

[5] URL:http://www.nutricion.org/publicaciones/revista_agosto _03/Funcionales/UEvitaminasminerales.pdf

1Acceptable risk level:

of immediate action $(\leq 0,02$ rel.units. $)$-eliminated the growth of morbidity associated with exposure to the estimated fact or and the state of discomfort can occur only in a few cases in sensitive people;

prolonged (chronic) exposure $(\leq 0,05)$, as well as specific actions (carcinogenic effects, 10-6-10-5) - the level of risk of an adverse effect, which does not require additional measures to reduce it and evaluated as an independent, small in relation to the risks that exist in the daily activities and life of the population. No adverse health and environmental tendency. 